$\widehat{\mathcal{O}}_{\text {doi: } 10.3765 / \text { sp.2.1 }}^{\text {Semantics \& Pragmatics Volume 2, Article 1: 1-7, } 2009}$

\title{
Bishop Sentences and Donkey Cataphora: A Response to Barker and Shan*
}

\author{
Paul Elbourne \\ Queen Mary, University of London
}

Received 2008-05-08 / Revised 2009-01-23 / Published 2009-01-27

\begin{abstract}
Some issues are raised concerning the treatment of donkey cataphora and bishop sentences in Barker \& Shan 2008.
\end{abstract}

Keywords: donkey anaphora; dynamic semantics; situation semantics; bishop sentences

\section{Introduction}

In the first volume of this journal, Barker \& Shan (2008) published an analysis of donkey anaphora that deserves to be discussed further. In the interest of brevity, I will not try to summarize their theory but will assume knowledge of it. And I confine my comments to two areas: Barker \& Shan's (2008) remarks on donkey cataphora (section 2); and their treatment of bishop sentences (section 3).

\section{Donkey Cataphora}

Donkey cataphora is a configuration in which a pronoun precedes and depends for its interpretation on an indefinite that does not c-command it. Barker \& Shan (2008: 5-6, 35) claim that an account of donkey anaphora based on situations (such as Elbourne 2005) fails to predict the following contrast involving donkey cataphora, where the pronouns are to be read as donkey anaphors:

* It is an honor to be invited to comment on Barker \& Shan's (2008) elegant article. Thanks to the editors of Semantics \& Pragmatics for the invitation and to Chris Barker for useful discussion. All errors are mine.

(C2009 Paul Elbourne

This is an open-access article distributed under the terms of a Creative Commons NonCommercial License (creativecommons.org/licenses/by-nc/3.o). 
Paul Elbourne

(1) a. A farmer beats a donkey if he owns it.

b. *He beats it if a farmer owns a donkey.

On the other hand, because the system in Barker \& Shan 2008 incorporates "a default of processing from left to right" that "rules out examples in which a donkey pronoun precedes its antecedent" (Barker \& Shan 2008: 35), this system predicts this contrast.

I would agree with Barker \& Shan to the following extent: my theory in Elbourne 2005 does not make the data in (1) fall out immediately, with reference to no further resources. But I see no reason to believe that it would not account for these data in a non-stipulative manner when combined with independently needed theories. I will offer some very brief thoughts on how one might go about this when faced with the data in (1). But, as I will then show, the relevant data turn out to be more complicated than this anyway, and more complicated than allowed for by Barker \& Shan.

Let us begin our sketch of an analysis of (1) by examining the following pair of sentences:

(2) a. $\mathrm{John}_{i}$ is upset if he ${ }_{i}$ sees a donkey.

b. ${ }^{*} \mathrm{He}_{i}$ is upset if $\mathrm{John}_{i}$ sees a donkey.

(2b) seems to be ungrammatical because of a violation of Principle $\mathrm{C}$ of the Binding Theory (Chomsky 1981). But that means that an if-clause postposed to a sentence S must be c-commanded by S's subject. But then that means that the ungrammaticality of ( $1 \mathrm{~b})$ is not mysterious when viewed in the light of the theory in Elbourne 2005. That work contained an analysis of if-clause donkey sentences like (3a) that followed Berman (1987) in assuming that the basic structure of examples like (3a) was (3b) (Elbourne 2005: 51-52)

a. If a man owns a donkey, he (always) beats it.

b. [[Quantificational-Adverb [if $\left.\left.\left.S_{1}\right]\right] S_{2}\right]$

In other words, the Elbourne 2005 analysis predicts that a pronoun will be interpretable as a donkey pronoun if it is in the nuclear scope of a quantificational adverb whose restrictor contains an appropriate indefinite. It provides no mechanism for donkey-cataphoric interpretation of the pronoun he in (1b), which, since it is not in the scope of any operator, is plausibly interpreted only as referential.

What about the grammaticality of (1a)? I suspect that the key here will lie in analyzing (1a) as a generic of the kind seen in (4). 
Bishop Sentences and Donkey Cataphora

(4) A lion has a bushy tail.

Krifka et al. (1995) analyze generic sentences as involving a phonologically null adverb GEN quantifying over situations in a manner compatible with the analysis of donkey sentences in Elbourne 2005. The restrictor for this quantification, in both (1a) and (4), would be constructed pragmatically (Krifka et al. 1995: 31); and the if-clause in (1a) would presumably be adjoined relatively low, perhaps to $\mathrm{VP}$, as argued above. The pronouns in the if clause in (1a) could then be analyzed as donkey pronouns picking up entities introduced in the pragmatically constructed restrictors.

I will not attempt to spell out this analysis in any more detail here, however. This is partly because of uncertainties surrounding the exact compositional semantics of generic sentences on the above analysis (Rimell 2004). And it is partly because of complications in the data, to which I now turn.

Barker \& Shan (2008: 6) point out that some examples of donkey cataphora are quite acceptable. An example is (5), from Chierchia 1995: 129.

(5) If it is overcooked, a hamburger doesn't taste good.

As they acknowledge (Barker \& Shan 2008: 6), this is unexpected on their theory. And there are plenty of other examples of grammatical donkey cataphora where (5) came from, displaying various patterns in the ordering of pronouns and indefinites (Chierchia 1995: 130):

(6) a. If she ${ }_{i}$ finds it ${ }_{j}$ spectacular, a photographer $_{i}$ takes many pictures of a landscape . $_{\text {. }}$

b. If it ${ }_{i}$ enters his ${ }_{j}$ territory, a pirate ${ }_{j}$ usually attacks a $\operatorname{ship}_{i}$.

c. If it ${ }_{i}$ spots a mouse $_{j}$, a cat ${ }_{i}$ attacks it $_{j}$.

d. If a foreigner ${ }_{i}$ asks him $_{j}$ for directions, a person from Milan $_{j}$ replies to $\operatorname{him}_{i}$ with courtesy.

These examples all involve an if-clause at the start. Can we at least draw a firm generalization to the effect that donkey cataphora is ungrammatical when a pronoun in a main clause relies for its interpretation on an indefinite in a postposed if-clause, as in (1b)? Actually, we cannot do this, as shown by the following examples:

(7) a. " $\mathrm{It}_{i}$ doesn't taste good if a hamburger ${ }_{i}$ is overcooked.

b. John won't eat it $i_{i}$ if a hamburger ${ }_{i}$ is overcooked. 
As (7a) shows, it does not seem to be possible to interpret a pronoun in subject position in a main clause as a donkey pronoun linked to an indefinite in a postposed if-clause, as Chierchia (1995: 132) has already pointed out. But, interestingly, (7b), with the pronoun in object position, seems to be quite acceptable. It is perhaps significant that the pronoun is in the scope of the if-clause in (7b) but not in (7a), assuming once more that the if-clause is adjoined below the subject.

I will not attempt to delve further into this matter in the present article. But I think that we should conclude that Barker \& Shan's (2008) principled ruling out of examples in which a donkey pronoun precedes its antecedent is problematic, since we have seen many such examples that are in fact grammatical. Meanwhile, there is a plausible means of ensuring that ( $1 \mathrm{~b}$ ) is predicted to be ungrammatical even by theories like that in Elbourne 2005. But the complexity of the data in this area and the complications in one relevant sub-theory (the analysis of generics) means that no conclusions can be drawn at this stage about a detailed compositional semantics for these cases. The subject is in need of a thorough review.

\section{Bishop Sentences}

In Elbourne 2005: 145-146, I lay out the following dilemma for theories that deal with donkey anaphora by dynamic binding and not by means of descriptive content. In contrast to (8a), (8b) does not have a donkey anaphoric reading:

(8) a. If a bishop meets a bishop, he blesses him.

b. *If a bishop and a bishop meet, he blesses him.

If we have a sentence like (8b) in which the two indefinites involve different descriptive content, however, the result is quite acceptable on a donkey anaphoric reading:

(9) If a bishop and a nun meet, he blesses her.

The challenge for the theories in question is the following: to deal with (9) they need to let the indefinites in a bishop and a nun bind the pronouns in the main clause; but then whatever mechanism they use to do this will automatically ensure that the pronouns in the main clause of (8b) are bound by the indefinites in a bishop and a bishop. The difference in descriptive content between the two cases is irrelevant, since the theories in question, 
Bishop Sentences and Donkey Cataphora

by definition, do not use descriptive content in order to establish donkey anaphora.

Barker \& Shan's (2008) theory is a theory of the type in question. They inform us that their theory successfully produces donkey anaphora in cases like (9) (Barker \& Shan 2008: 34). They are thus faced with the task of explaining how they can avoid predicting it in cases like (8b).

Their response to this challenge is to say that the donkey anaphoric reading of $(8 b)$ is grammatical in principle but awkward because there is no way of "deciding which of the possible anaphoric relations is the intended one" (Barker \& Shan 2008: 34). That is, there is no way of deciding whether the first or second occurrence of a bishop is to bind he, and likewise with him. To support this position, they refer to the sentences in (10), where anaphora resolution is also tricky (Barker \& Shan 2008: 34).

(10) a. If John and Bill meet, he falls asleep.

b. If a butcher and a baker meet, he pays him.

c. If a man walking a dog and a woman walking a dog meet, it barks at it.

These sentences, they claim, are awkward in precisely the way that (8b) is.

I am doubtful, however, that the ungrammaticality of ( $8 \mathrm{~b})$ can be explained by pointing out that each pronoun is such that there is no way of deciding whether the first or second occurrence of a bishop is to bind it. For exactly the same state of affairs obtains in the grammatical (8a). As I pointed out in Elbourne 2005: 153, some informants report that (8a) is ambiguous between a reading in which "the first bishop blesses the second bishop" and one in which "the second bishop blesses the first bishop." This makes no difference to the grammaticality of that example. So it is difficult to see why an analogous state of affairs would make a difference to the acceptability of a putatively grammatical $(8 \mathrm{~b})$.

It is true that the closely parallel (1ob), with no disambiguating context, is rather awkward, and it is plausible to maintain that this has something to do with the uncertainty over what anaphoric links are to be understood. (It is fine, of course, if we preface it with a declaration that butchers, or alternatively bakers, are particularly good at paying their debts to other tradesmen.) One might speculate that the reason that (8a) is fine even in the absence of a compelling reason to understand one anaphoric configuration over another is that which anaphoric configuration is chosen has no effect on truth conditions in (8a), whereas in (1ob), obviously, it would have such 
an effect. But, be that as it may, the presence in the grammatical (8a) of the factor that allegedly makes (8b) unacceptable surely means that this factor cannot, in fact, be responsible for the status of $(8 b)$.

\section{Conclusion}

There are other areas where one might question whether Barker \& Shan's (2008) treatment of pronouns achieves good empirical coverage. In particular, I do not at the moment see how this theory can deal with the following: examples like he who must not be named (Elbourne 2005: 120), where the material before the relative clause seems to be equivalent to the male person; the pattern of strict and sloppy readings for sentences involving donkey pronouns and elliptical continuations (Elbourne 2005: 68-79); and the behavior of the Japanese pronouns kare and kanozyo (Elbourne 2005: Chapter 5). I will not go into details on these matters here, however, but will refer interested readers to my previous work.

Overall, although I am deeply impressed by Barker \& Shan's (2008) elegant article, I am not, as yet, convinced by it. But it must be admitted that further work is required on some of the data discussed in the present article, especially the donkey cataphora facts.

\section{References}

Barker, Chris \& Chung-chieh Shan. 2008. Donkey anaphora is in-scope binding. Semantics \& Pragmatics 1. 1-46. doi:10.3765/sp.1.1.

Berman, Stephen. 1987. Situation-based semantics for adverbs of quantification. In James Blevins \& Anne Vainikka (eds.), Studies in semantics (University of Massachusetts Occasional Papers in Linguistics 12), 46-68. Amherst: GLSA.

Chierchia, Gennaro. 1995. Dynamics of meaning: Anaphora, presupposition, and the theory of grammar. Chicago: University of Chicago Press.

Chomsky, Noam. 1981. Lectures on government and binding. Dordrecht: Foris.

Elbourne, Paul. 2005. Situations and individuals. Cambridge, Mass.: MIT Press. Krifka, Manfred, Francis Jeffry Pelletier, Gregory Carlson, Alice ter Meulen, Godehard Link \& Gennaro Chierchia. 1995. Genericity: an introduction. In Gregory Carlson \& Francis Pelletier (eds.), The generic book, 1-124. Chicago: University of Chicago Press. 
Bishop Sentences and Donkey Cataphora

Rimell, Laura. 2004. Habitual sentences and generic quantification. Proceedings of WCCFL 23. 663-676.

Paul Elbourne

Department of Linguistics

Queen Mary, University of London

London E1 4NS

UK

p.d.elbourne@qmul.ac.uk 